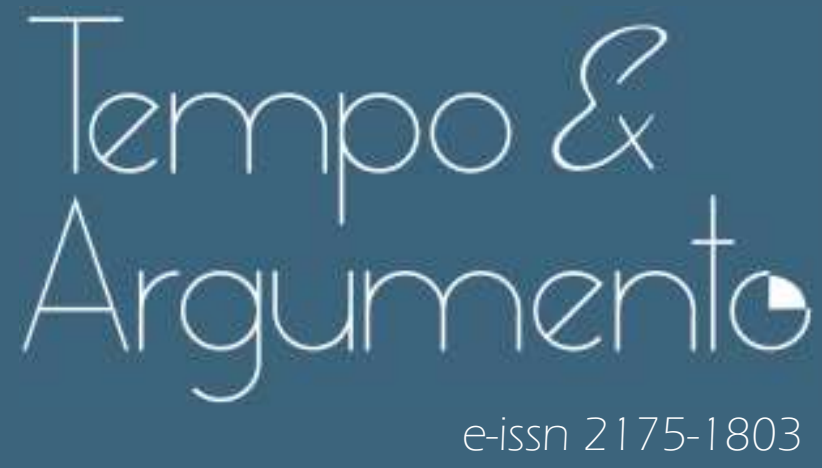

\title{
História e reparação em espaços de memória de violações de Direitos Humanos na América Latina
}

- Adrianna Setemy

Doutora em História Social pela Universidade Federal do Rio de Janeiro (UFRJ).

Professora do Departamento de História da Universidade Estadual de Maringá (UEM)

e do Mestrado Profissional em Ensino de História - Profhistória, da Pontifícia

Universidade Católica do Rio de Janeiro (PUC-Rio).

Rio de Janeiro, RJ - BRASIL

lattes.cnpq.br/3002237488278136

asetemy@gmail.com

(D) orcid.org/0000-0002-6213-5088

Para citar este texto:

SETEMY, Adrianna. História e reparação em espaços de memória de violações de Direitos Humanos na América Latina [Debate]. Revista Tempo e Argumento,

Florianópolis, v. 13, n. 34, e0401, set./dez. 2021

dol dx.doi.org/10.5965/2175180313342021 e0401

Recebido: 23/12/2020

Aprovado: 09/08/2021 
História e reparação em espaços de memória de violações de Direitos Humanos na América Latina Adrianna Setemy

A cidade é um espaço que contém múltiplos sinais e marcas de histórias individuais, projetos coletivos, tragédias privadas e públicas assinaladas em nomes de ruas, edifícios, nomes de praças e de monumentos que cumprem sua função ao mesmo tempo em que buscam transmitir mensagens. Os fatos considerados históricos se expressam no espaço topográfico das cidades, onde capas de memória se sobrepõem e se condensam ao longo do tempo. Ainda que permeados de marcas, muitas vezes os espaços das cidades tornam-se esvaziados de seu significado social, histórico e político em decorrência do ritmo acelerado da vida cotidiana. Percebe-se que entre o estabelecimento de políticas públicas memoriais visando à celebração e à homenagem, e a divulgação de conteúdos e conhecimento histórico que resulte em uma conscientização dos sujeitos que circulam pelos espaços de memória, há uma distância que precisa ser discutida com cuidado. Dessa forma, é fundamental pensar sobre como se desenvolve o processo de escolha, preservação e gestão de espaços de memória relacionados às últimas ditaduras militares na América Latina, com o objetivo de elucidar o desafio permanente de “conferir sentido" histórico a esses espaços sob a ótica dos Direitos Humanos.

A contemporaneidade das demandas por sinalização de memórias traumáticas e o desafio da gestão de passados traumáticos

A Declaração Universal dos Direitos Humanos (1948), e outros instrumentos legais dela derivados, reconhecem a memória e a "verdade histórica”1 como direitos inalienáveis do homem. O registro e monumentalização

\footnotetext{
O direito à verdade foi definido como aquele que têm as vítimas de graves violações aos direitos humanos e seus familiares de conhecer a verdade do ocorrido, em particular a identidade dos autores e as causas, os fatos e as circunstâncias em que os fatos foram produzidos. Além dessa dimensão individual, o direito à verdade tem uma dimensão social e coletiva, ligada ao direito dos povos de conhecer seu passado para assim construir uma memória histórica. No âmbito do sistema interamericano de proteção aos direitos humanos, tanto a Comissão como a Corte Interamericana de Direitos Humanos reconheceram em numerosos pronunciamentos o direito à verdade como um direito implícito da Convenção Americana sobre Direitos Humanos. O conteúdo e o alcance do direito à verdade foram descritos, no âmbito do direito internacional referente aos Direitos Humanos, nos seguintes documentos: 1) Resolução da Comissão de Direitos Humanos da ONU (Res. 2005/66), Decisão do Conselho de Direitos Humanos 2/105 e as Resoluções do mesmo órgão (9/11 e 12/12); 2) Resolução do Conselho de Direitos Humanos que cria o Relator Especial sobre a promoção da Assembleia Geral da OEA sobre o direito à verdade, à justiça, à reparação e às garantias de não repetição (A/HRC/18/L.2); 3) as Resoluções da Assembleia Geral da OEA sobre o direito à verdade (AG/RES. 2175 (XXXVI-O/06), AG/RES. 2267 (XXXVII-O/07), AG/RES. 2406 (XXXVIII-O/08), AG/RES. 2509 (XXXIX-O/09), AG/RES 5086/10, e
} 
dos locais onde ocorreram acontecimentos traumáticos pode ser entendido como parte de um esforço contemporâneo em garantir o direito à memória, verdade e justiça das vítimas de graves violações de direitos humanos e de seus descendentes.

Nos anos 1990, foi cunhada na França a expressão dever de memória, que, em poucas palavras, remete à ideia de que memórias de sofrimento e opressão geram obrigações, por parte do Estado e da sociedade, em relação às comunidades portadoras dessas memórias. A origem da noção do dever de memória estaria no processo que teve início nos anos 1970 de ressignificação do discurso memorial ligado ao Holocausto de milhares de judeus pelo regime nazista. A construção de um discurso memorial de natureza reivindicativa, contra o esquecimento, mas também pelo reconhecimento oficial do papel dos agentes públicos no genocídio do povo judeu e punição dos culpados pelos crimes de violação aos Direitos Humanos, bem como os desdobramentos objetivos das ações pautadas nesse discurso, fizeram com que o dever de memória ligado ao Holocausto se constituísse em um paradigma para outros grupos que buscam afirmar no espaço público memórias que evocam processos de violência ou de discriminação (HEYMANN, 2006, p. 4).

Quando a memória de um grupo emerge no espaço público, afirmando sua identidade, passa a disputar o reconhecimento dos diferentes grupos sociais e a buscar espaço no discurso histórico a partir de uma revisão das interpretações do passado. O objetivo dessa disputa é reparar o silêncio e/ou a invisibilidade desses grupos e promover sua integração à história nacional a partir do ponto de vista das vítimas. Entre suas reivindicações estão a luta por manter viva essa memória, por espaço no discurso histórico, por figurar nos livros e manuais escolares, por ver-se incluído no calendário oficial de comemorações e representado em monumentos e memoriais. A esse respeito, o historiador Henry Rousso afirma que, atualmente, lembrar-se e afirmar a culpa e o arrependimento

AG/RES 5177/11); 4) a Convenção Internacional para a Proteção de todas as Pessoas contra as Desaparições Forçadas, que é o primeiro instrumento internacional do direito internacional dos direitos humanos que reconhece o direito à verdade como um direito autônomo (Preâmbulo e art. 24, par. 2). 
(por parte do Estado e seus agentes) correspondem a posturas positivas, enquanto que o esquecimento e a anistia tornaram-se socialmente inaceitáveis (ROUSSO, 1998).

Na América Latina, há especificidades nas maneiras como os atores de cada país introduzem e dão sentido a seus passados ditatoriais nas lutas e confrontos políticos travados no presente. Um traço compartilhado entre os países do continente é que o passado recente não está fechado e é parte central do cenário político atual. As contas com o passado não estão saldadas, nem em termos institucionais nem em termos simbólicos. À medida que passa o tempo e se torna possível conceber uma distância temporal entre passado e presente, interpretações contrapostas e mesmo rivais sobre esse passado e suas memórias se instalam no centro do debate político e cultural, tornando-se questões públicas inevitáveis (JELIN, 2002, p. 4).

No âmbito do Sistema Interamericano de Direitos Humanos, a Corte Interamericana de Direitos Humanos entende que a criação e a manutenção de "Lugares de Memória" são um modo de reparação simbólica das vítimas e uma medida de garantia da não repetição, já que esses espaços poderão servir como canal de comunicação com as gerações futuras. Conforme a definição proposta por Pierre Nora, o “Lugar de Memória” não surge naturalmente. É uma criação e resulta de um esforço do Estado e/ou da sociedade para que certos eventos não sejam esquecidos. Esse surgimento "não natural" de locais para lembrar do que nunca mais deve se repetir atende a um "dever de memória" em relação aos traumas do passado recente e justificam sua proteção pelo valor histórico e político que portam. Um documento elaborado pelo Instituto de Políticas Públicas em Direitos Humanos do MERCOSUL - IPPDH, em 2012, apresenta a seguinte definição de Lugares de Memória, visando à elaboração de Políticas Públicas de memória para a América Latina: "são considerados lugares de memória todos aqueles lugares onde se cometeram graves violações aos direitos humanos, ou onde se resistiram ou se enfrentaram essas violações, ou que por algum motivo as vítimas, seus familiares ou as comunidades os associam com tais acontecimentos, e que são utilizados para recuperar, repensar, e transmitir o conhecimento sobre processos traumáticos, e/ou para homenagear e reparar 
as vítimas." (IPPDH, 2012, p. 16). A Corte destaca a importância de definir e criar esses espaços públicos como uma ferramenta através da qual a sociedade e especialmente as vítimas poderão lidar com o trauma e fortalecer a construção de regimes democráticos (IPPDH, 2012).

Segundo Elizabeth Jelin, as iniciativas espaciais que vêm se desenvolvendo na América Latina têm origem dentro dos movimentos de Direitos Humanos e estão relacionadas a uma cultura dos Direitos Humanos que emergiu na segunda metade do século XX (JELIN, 2003). Ao analisar os processos de redemocratização pós-ditaduras no cone sul, a autora observou que as sociedades latino-americanas são distintas em suas formas de promover um enfrentamento com o passado traumático. Entretanto, a reivindicação por espaços de memória para os sobreviventes e os familiares das vítimas vem se apresentando como uma demanda comum cada vez mais contundente (JELIN, 2003). Essa demanda por parte das vítimas e familiares dialoga com o discurso dominante nas esferas governamentais que, segundo Ludmila Catela, após o discurso de reconciliação típico dos anos 1980 e 1990, nos anos 2000 passaram a afirmar a necessidade de criação de "instituições para o futuro", como parte de um processo de "institucionalização das memórias" das ditaduras (CATELA, 2014, p. 02). Em diferentes países da América Latina, multiplicam-se no espaço público as marcas de memórias reivindicadas por vítimas e familiares de vítimas das ditaduras do século XX, como forma de homenagear e reparar simbolicamente os herdeiros do trauma pelos danos promovidos pelo Estado.

O crescente número de espaços de memória das violações de Direitos Humanos nas últimas ditaduras latino-americanas indica a persistência de um "passado que não quer passar"2, e coloca para os pesquisadores duas demandas prementes. A primeira consiste em historicizar o processo que resultou na demarcação dos espaços de memória. A segunda, consiste em, a partir daí, refletir a respeito da sua eficiência enquanto instrumento que vem sendo utilizado pelos Estados na gestão de passados sensíveis, bem como o papel do

\footnotetext{
O historiador Henry Rousso (CONAN, 2013) cunhou a expressão "Le passe qui ne passe pas" para referir-se à memória da ocupação de Vichy pelos alemães na II Guerra Mundial. A expressão popularizou-se e hoje é utilizada para designar o imperativo memorial que prevalece na sociedade francesa, na qual se discutem incessantemente, na cena pública, temas traumáticos do passado como, por exemplo, a ocupação nazista, a guerra na Argélia e a sua colonização.
} 
historiador nesses espaços públicos, a fim de que os espaços de memória não se resumam ao cumprimento de um dever de memória, mas sejam eficazes como ferramenta para promoção de valores democráticos, humanitários e da cultura dos Direitos Humanos.

Os significados e os sentidos dos espaços de memória das violações de Direitos Humanos nas ditaduras militares latino-americanas

A criação dos lugares de memória é uma ferramenta à disposição dos Estados para cumprirem com suas obrigações em matéria de verdade, memória, reparação e justiça na transição de períodos que se caracterizaram por graves violações aos Direitos Humanos. A materialidade desses espaços carrega evidências objetivas e subjetivas das violações ali ocorridas, ao mesmo tempo em que constitui um patrimônio histórico e cultural para as futuras gerações.

As referências aos espaços físicos onde as violências foram cometidas sempre integraram as narrativas orais e memórias das vítimas e dos familiares de vítimas das ditaduras, assim como os documentos oficiais sobre os crimes cometidos pelos agentes do Estado. Já na etapa inicial dos processos de democratização que se seguiram aos regimes ditatoriais, os depoimentos das vítimas da violência de Estado descreviam edificações e espaços onde transcorreram as experiências de repressão e resistência. Através desses testemunhos é possível construir uma topografia desses espaços, assinalando seus usos, sua organização, divisão e funcionalidade (FELD, 2010).

Os testemunhos e a documentação oficial - que foi sendo produzida e revelada ao longo dos processos de redemocratização -, fazem referência a aspectos objetivos e subjetivos que permitem representar a materialidade dos espaços de repressão e resistência durante as ditaduras. Reunir esse conjunto de evidências é fundamental para que se possa identificar e sinalizar esses espaços, que podem se tornar "visíveis" independente da existência de registro imagéticos e marcas materiais da violência. Entretanto, o testemunho deve ocupar um papel central na gestão desses espaços, pois a eficiência na sua função de reparação está diretamente relacionada à sua capacidade de dialogar constantemente com os trabalhos de resignificação do passado e de ter sentido 
exemplar, educativo e não apenas um caráter nostálgico. Segundo Ludmila Catela, os espaços de memória são eficazes no trabalho de ressignificação do passado traumático sob a ótica dos Direitos Humanos, quando se convertem em espaços de ação política, de diálogo, circulação e encontro de diferentes grupos, com potencialidades para promover debates entre diferentes lógicas repressivas do passado e do presente e, a partir daí, refletir a respeito das formas de violência de ontem e de hoje (CATELA, 2014, p. 331).

Os espaços de memória são construídos especificamente para realizar "trabalhos de memória" (JELIN, 2002), mas não têm necessariamente um vínculo físico, emocional ou simbólico com os acontecimentos que buscam evocar (IPPDH, 2012, p. 18-19).

Inicialmente, podem-se distinguir dois tipos de espaços de memória:

- Lugares que guardam um vínculo material direto com os fatos históricos do passado, como por exemplo, o Estádio Nacional do Chile, o Espaço de Memória Londres 38, em Santiago (Chile); túnel Zuzu Angel, no Rio de Jeneiro (Brasil); Memorial da Resistência, em São Paulo (Brasil); Museu da Memória, em Rosário (Argentina).

- Lugares e marcas que resultaram, posteriormente aos fatos históricos, da iniciativa e do trabalho de instituições, grupos e autoridades, como por exemplo, o Parque da Memória (Bs As); o LUM (Lugar de Memória, Tolerância e Inclusão Social, no Peru); Museu da Memoria e dos Direitos Humanos, em Santiago (Chile); Museu da Memória, de Ayacucho (Peru); Museu da Memória (MUME), em Montevidéu.

Apesar de distintos quanto à natureza, esses espaços têm em comum o propósito pelo qual devem ser criados ou já foram criados: colocar na esfera pública de maneira destacada um dispositivo que permita evocar as experiências das vítimas de violações de Direitos Humanos para além do tempo que seus familiares ou outros promotores da homenagem possam assegurar o exercício dessas memórias.

A voz da vítima e/ou de seus familiares é que atribui significado ao espaço de memória. Para que um espaço de memória fomente a reflexão pública a respeito do passado recente traumático na América Latina é fundamental que os sujeitos das narrativas contadas a partir dos espaços de memória sejam as 
vítimas da violência que ali se passou. Isso não equivale a sacralizar esses espaços (JELIN, 2010), embora os espaços de memória muitas vezes sirvam para abrigar o culto à memória dos mortos e desaparecidos.

Tendo em vista o fortalecimento de uma identidade social democrática dos espaços de memória, espera-se que estejam orientados em direção ao futuro e que não se limitem a uma simples reiteração do passado. Isso porque o conflito social sobre como processar e resignificar o passado repressivo recente é permanente e pode se tornar mais agudo conforme o clima político e cultural de cada época. Afinal, toda memória, assim como a história, é objeto de disputas, conflitos e lutas, e por isso tem um caráter sempre parcial, mutável. Nesse sentido, o processo de construção social da memória do passado recente traumático na América Latina é um processo permanente, por completo inacabado, insuficiente e assinalado por avanços, retrocessos e pela aparição de novos e urgentes problemas a serem resolvidos. Como afirma Ricardo Vinyes, a memória é fascinante porque tem aparência de verdade e perpetuidade, quando na verdade é expressão cultural, simbólica, narrativa e política de uma conjuntura. Por isso, está em constante transformação (VINYES, 2018, p. 14).

Uma coisa é certa: em qualquer sociedade jamais haverá uma única memória, uma única interpretação do passado que seja compartilhada por todos. Em alguns períodos históricos, dependendo do grupo que vença as disputas políticas do seu tempo, uma versão será mais aceita que outra. Em alguns casos, uma versão pode chegar a tornar-se hegemônica em relação a outras, imposta. Mas ainda assim, sempre haverá outras histórias, outras interpretações a respeito do sentido do passado e da memória desse passado, ainda que escondidas, subterrâneas. Por esse motivo, os espaços de memória sempre serão espaços de disputas políticas entre memórias rivais. A simples definição e demarcação de um espaço não garante o cumprimento do objetivo principal que é transmitir, de forma dinâmica e atualizada com os problemas do presente, as experiências ocorridas naquele lugar em termos de graves violações de Direitos Humanos.

O sentido atribuído aos espaços de memória dependerá de Políticas Públicas eficazes que proponham a transmissão de mensagens que possam ser percebidas pelos cidadãos que passam por esses lugares diariamente em meio 
ao ritmo acelerado da vida urbana. Transformar um espaço onde se vivenciou experiências de repressão ou resistência em outro, de memória, requer vontade política para recuperá-lo, demarcá-lo e dotá-lo de recursos que restituam ou atribuam ao lugar sua historicidade ou seu simbolismo e o constitua em espaço de uso público para resignificar memórias, conhecer o passado e promover a ação cívica das lutas por Direitos Humanos e por justiça no presente.

Com isso, deixam de ser apenas uma amostra da violência de Estado e passam a cumprir um papel-chave na transmissão de memórias e experiências traumáticas, tramas sobrepostas que permitem demonstrar que alguns aspectos da violência de Estado, embora exacerbados durante as ditaduras, não se restringem aos marcos temporais institucionais que definem o começo e o fim dos regimes ditatoriais. É assim que os espaços de memória poderão ser convertidos em "espaços de consciência", ferramentas através das quais as sociedades poderão lidar com o passado recente traumático e fortalecer a construção de regimes democráticos.

Nesse sentido, pode-se dizer que a multiplicação de espaços de memória na América Latina faz parte do processo de Justiça de Transição pelo qual os países vêm passando e que envolve a elaboração do passado recente traumático através de políticas públicas de memória. Segundo Antônio Costa Pinto, o conceito de justiça transicional surgiu no final da década de 1980 e início da década de 1990 em resposta às mudanças políticas ocorridas no Leste Europeu e na América Latina, a partir da junção de demandas por justiça e transição democrática (PINTO, 2010, p. 2).

A justiça de transição consiste em um componente de um processo de mudança de regime, cujas diferentes facetas são parte integrante desse processo incerto e excepcional que tem lugar entre a dissolução do autoritarismo e a institucionalização da democracia, envolvendo toda uma série de medidas tomadas ao longo da redemocratização, as quais vão além da mera

\footnotetext{
A definição de "espaços de consciência" é dada pela International Coalition of Sites of Conscience (Ver: https://icom.museum/en/committee/international-coalition-of-sites-ofconscience/.) Para a coalizão, qualquer memorial, museu, local histórico, iniciativa de memória ou organização não governamental que se comprometer com a transformação dos lugares que preservam o passado em espaços dinâmicos que promovam a ação cívica das lutas atuais por Direitos Humanos e justiça é um Local de Consciência.
} 
criminalização de perpetradores, colaboradores e agentes da repressão, implicando uma grande diversidade de esforços extrajudiciais, tais como investigações históricas oficiais sobre a ação repressiva das ditaduras, saneamentos, reparações, dissolução de instituições legadas do regime anterior e comissões da verdade. Nesse sentido, segundo o autor, pode-se pensar a justiça de transição como sendo, ao mesmo tempo, uma consequência e uma parte do processo de transição democrática, que visa enfrentar o legado de ditaduras (PINTO, 2013, p. 24-25).

As políticas públicas de memória, dentre as quais a identificação e criação de espaços de memória, estão diretamente relacionadas aos esforços de fortalecimento das democracias pós-ditatoriais latino-americanas, em duas dimensões:

- Reconhecimento institucional dos fatos e das vítimas. O reconhecimento institucional é sinônimo de responsabilização e reparação, de fato (judicial, por exemplo) e/ou simbólica, como é o caso da criação de espaços de memória.

- Estímulo ao debate público sobre o passado como elemento constitutivo da criação de uma identidade pós-ditatorial.

Essas duas dimensões da relação entre políticas públicas de memória e fortalecimento das democracias se integram na medida em que a criação de espaços de memória deve promover o debate público e a divulgação do conhecimento histórico para um público cada vez mais amplo, a fim de esclarecer, bem como evitar o silêncio e a negação de acontecimentos obscuros e dolorosos, fomentando e difundindo uma identidade democrática, uma cultura dos Direitos Humanos e uma repulsa à violência do Estado e ação dos agentes públicos envolvidos. Afinal de contas, a memória não se compõe apenas pela lembrança de experiências vividas, mas também por recordações transferidas ou adquiridas (VINYES, 2018, p. 14).

A reflexão pública a respeito do passado recente traumático é um importante elemento constitutivo das identidades democráticas pós-ditatoriais. A ausência desse debate público dificulta o processo de consolidação das democracias bem como o apreço dos diferentes setores sociais a valores democráticos e a princípios humanitários. 
Sem dúvida a investigação historiográfica deve integrar essa reflexão pública. Se, por um lado, as Comissões de Verdade ${ }^{4}$, como parte da Justiça de Transição, empenharam-se em instituir uma "verdade jurídica" ancorada na memória das vítimas, à História cabe o dever de ofício de produzir um conhecimento verossímil, construído a partir de fontes diversificadas que respondem a problemas formulados no presente. Entretanto, diferente da verdade jurídica, a verdade histórica não é única, tampouco definitiva.

Nas últimas duas décadas, com a gradativa abertura dos "arquivos da repressão" em alguns países, associada à mobilização de organizações da sociedade civil, a historiografia sobre as ditaduras militares na América Latina vem se consolidando, sobretudo no espaço acadêmico. Contudo, resta aos historiadores legitimar-se entre um público cada vez mais amplo como mediador reflexivo entre passado e presente, tendo em vista divulgar um conhecimento histórico verossímil acerca do passado recente traumático, construído a partir do ponto de vista das vítimas e com precisão empírica que permita enfrentar, com base em argumentação científica, outras narrativas historiográficas e memorialísticas que se prestam a aplaudir e glorificar as ditaduras e seus agentes.

Os espaços de memória podem ser pensados como um instrumento concreto de permanente produção de conhecimento histórico, que transmite uma verdade jurídica e um saber histórico comprometido com a divulgação de documentos de diferentes naturezas e com o respeito pelos Direitos Humanos e

\footnotetext{
${ }^{4}$ Na segunda metade do século XX, quase todos os países da América Latina passaram por períodos de repressão política liderada por governos autoritários. Nos regimes pós-ditaduras, a maioria dos governos democráticos tem criado Comissões de Verdade para investigar as violações ocorridas. Dentre elas, destacam-se: Comisión Nacional de Investigación de Desaparecidos Forzados, Bolívia (1982); Comisión Nacional sobre La Desaparición de Personas (CONADEP), Argentina (1983); Comisión de Investigación Parlamentaria sobre Personas Desaparecidas, Uruguai (1985); Comisión Nacional de Verdad y Reconciliación de Chile (1990); Comissão de Verdade para El Salvador (1991); Corporación Nacional de Reparación y Reconciliación, Chile (1992); Comisión para el Esclarecimiento Histórico, Guatemala (1994); La Commission Nationale de Vérité et de Justice, Haiti (1995); Comisión de la Verdad y Reconciliación, Peru (2000); Comisión para la Paz, Uruguai (2000); Informe de la Comisión Institucional de la Verdad, Panamá (2001); Comisión Nacional sobre Prisión Política y Tortura, Chile (2003); Comisión de Verdad y Justicia, Paraguai (2004); Comisión Nacional de Reparación y Reconciliación, Colômbia (2005); Comisión de la Verdad del Ecuador (2007); Comisión de la Verdad y la Reconciliación, Honduras (2009); Comisión Asesora para la calificación de Detenidos desaparecidos, ejecutados políticos y víctimas de prisión política y tortura, Chile (2010); Comissão Nacional da Verdade, Brasil (2011).
} 
pelas liberdades fundamentais, conforme postulado pelo artigo 30 da Declaração Universal dos Direitos Humanos, de 1948. Ao mesmo tempo em que cumpre o papel de reparar simbolicamente os danos e sofrimentos das vítimas de violências perpetradas pelo Estado e seus agentes, os espaços de memória podem e devem servir para fomentar a reflexão das novas gerações que não sofreram diretamente as sequelas dos sistemas repressivos. Cabe aos historiadores propor dispositivos que permitam que os espaços de memória evoquem as vítimas da repressão para além do tempo que seus familiares ou outros "guardiões da memória" possam assegurar ou exercitar essa lembrança e, de maneira didática, transmitam às gerações futuras o conhecimento produzido a partir dessas memórias de forma a sensibilizá-los e alertá-los para as "fronteiras porosas" entre a violência e o espaço urbano (FELD, 2010).

Esses espaços se constituíram em meio à vida cotidiana dos cidadãos, a partir da mescla entre o visível e o clandestino, combinados em diferentes doses para atender o objetivo de eliminar toda forma de oposição às ditaduras instituídas. Por serem porosas e difusas, as fronteiras entre os espaços onde foram vivenciadas experiências de violência e a cidade, é possível afirmar que em alguma medida a sociedade, na época das ditaduras, foi testemunha das violências praticadas pelos agentes dos Estados. Se não colaborou, ao menos não denunciou. O que os espaços de memória hoje sinalizados e constituídos em diferentes cidades da América Latina nos contam é que a violência não esteve presente apenas nos "porões" das ditaduras, mas em espaços públicos e privados localizados em meio à dinâmica da vida cotidiana.

Dessa evidência pode-se depreender uma importante lição histórica: a sociedade escolheu não ver a violência que se passava diante de seus olhos, assim como nos dias de hoje passa indiferente pelos memoriais, pelas praças, ruas e pontes que evocam a memória da repressão. Indiferentes, no passado, hoje em dia alegam desconhecer o que se passava e ignoram as marcas da violência perpetrada pelos Estados durante as ditaduras. As marcas da memória espalhadas pelas cidades latino-americanas devem lembrar aos que visitam e circulam por esses espaços que as mortes, sequestros e desaparições foram possíveis e podem voltar a se repetir. Como um elo entre os mortos, 
desaparecidos e vítimas que sobreviveram ou que estão vivos, esses espaços devem ecoar continuamente a pergunta: "Como foi possível?" (CATELA, 2014, p. 331).

Segundo Ludmila Catela, a eficiência dos espaços de memória em "conferir sentido" ao passado recente traumático sob a ótica dos Direitos Humanos está na capacidade de concretizar suas ações em quatro esferas da memória:

- Difundir a ideia de que aquele espaço de memória é um patrimônio de todos;

- Exercitar regularmente práticas "comemorativas";

- Incentivar e divulgar pesquisas sobre os crimes e violações de Direitos Humanos;

- Desenvolver ferramentas pedagógicas para que os espaços de memória cumpram seu dever de dialogar com novas gerações e suas diversas realidades (CATELA, 2014, p. 332).

Diante de uma sociedade que escolheu não ver, os espaços de memória devem ser explorados pelos historiadores em sua capacidade potencial de atuar como suportes propagadores de memórias que permitem questionar setores da sociedade que, ainda hoje, dizem desconhecer a repressão ou que negam fatos e evidências, e assim constituírem-se enquanto instrumentos significativos de reflexão, de transparência, capazes de transformar experiências futuras a partir das cicatrizes deixadas pelo passado.

\section{Referência}

CATELA, Ludmila da Silva. Esas memorias... nos pertencen?: riesgos, debates y conflictos en los sítios de memória en torno a los proyectos públicos sobre los usos del pasado reciente em Argentina. Foro "Que es legitimo hacer en los sítios de memória? Núcleo Memoria: [s.n.], 2014.

CATELA, Ludmila da Silva. Memorias em escena: delas micro acciones de memoria a las políticas de Estado em Argentina. In: RELATÓRIO DE PESQUISA PARA A COMISSÃO ESTADUAL DA VERDADE DO RIO DE JANEIRO: políticas públicas de memória para o estado do Rio de Janeiro: pesquisas e ferramentas para a não-repetição. Rio de Janeiro: [s.n.], 2015. p. 321-333. 
CONAN, Eric; ROUSSO, Henry. Vichy, un passé qui ne passe pas. Fayard/Pluriel, 2013.

FELD, Claudia. El centro clandestino de detención y sus fronteras: algunas notas sobre testimonios de la experiencia de cautiverio en la ESMA. Recordar para pensar: memoria para la democracia. Santiago de Chile: [s.n.], 2010.

HEYMANN, Luciana. O"devoir de mémoire" na França contemporânea: entre a memória, história, legislação e direitos. Rio de Janeiro: CPDOC, 2006.

IPPDH - INSTITUTO DE POLÍTICAS PÚBLICAS EN DERECHOS HUMANOS MERCOSUL. Principios fundamentales para las políticas públicas sobre sítios de memoria. Buenos Aires: IPPDH, 2012.

JELIN, Elizabeth. Las conmemoraciones: las disputas em las fechas "in-felices". Madrid: siglo XXI España, 2002. (Memórias de la represión).

JELIN, Elizabeth; LANGLAND, Victoria. Monumentos, memoriales y marcas territoriales. Madrid: Siglo XXI, 2003.

JELIN, Elizabeth. ¿Qué papel cumplen los espacios para la memoria en nuestra sociedad? recordar para pensar: memoria para la democracia. Santiago de Chile: [s.n.], 2010.

PINTO, Antonio Costa. O passado autoritário e as democracias da Europa do sul. In: MARTINHO, Francisco Carlos Palomanes; PINTO, Antonio Costa. O passado que não passa: a sombra das ditaduras. Rio de janeiro: Civilização Brasileira, 2013. p. 24-25

PINTO, Simone Rodrigues. Direito à memória e à verdade: comissões de verdade na América Latina. Revista Debates, Porto Alegre, v. 4, n. 1, p. 128, 2010.

ROUSSO, Henry. La hantise du passé. Paris, Textuel, 1998.

VINYES, Ricard (dir.). Diccionario de La memoria colectiva. Barcelona: Gedisa, 2018. 